\title{
Comparative Study of Adsorption of Copper Ion onto Locally Developed and Commercial Chitosan
}

\author{
Sunday Anthony Akolo, Abulsalami Sanni Kovo \\ Department of Chemical Engineering, Federal University of Technology, Minna, Nigeria \\ Email: akolosunday@yahoo.com, kovo@futminna.edu.ng
}

Received 26 January 2015; accepted 28 February 2015; published 3 March 2015

Copyright (C) 2015 by authors and Scientific Research Publishing Inc.

This work is licensed under the Creative Commons Attribution International License (CC BY). http://creativecommons.org/licenses/by/4.0/

(c) (i) Open Access

\begin{abstract}
Chitosan synthesized locally with a degree of deacetylation $71 \%$ and chitosan with a degree of deacetylation $68 \%$ from Sigma Aldrich were used to investigate adsorption of $\mathrm{Cu}^{2+}$ ion in aqueous solution. The results obtained from equilibrium isotherm adsorption studies of $\mathrm{Cu}^{2+}$ ion were analyzed in five adsorption models namely: Langmuir, Freundlich, Temkin, Elovich and DubinRadushkevich. The isotherms equation was indicated to be well fitted to Langmuir, Freundlich, Temkin and Elovich under the concentration range studied. The kinetic parameters were evaluated utilizing the pseudo-first-order and pseudo-second-order equations, and the adsorption kinetics followed the mechanism of the pseudo-second-order equation for all systems studied, evidencing chemical sorption as the rate-limiting step of adsorption mechanism and not involving a mass transfer in solution. The FTIR studies revealed that the greater sorption of heavy metal was attributed to the large number of primary amine groups available on the surfaces of the chitosan and the abundant carboxyl groups on chitosan.
\end{abstract}

\section{Keywords}

Copper, Chitosan, Adsorption, Deacetylation

\section{Introduction}

The presence of heavy metal ions in the environment has received extensive attention due to their increasing release to the atmosphere. Chitin is the most abundant natural fiber next to cellulose and is similar to cellulose in many respects. The most abundant source of chitin is the shell of crab and shrimp. Chitosan was discovered in 1859 by Professor C. Rouget. Chitosan contains 2-acetamido-2-deoxy- $\beta$-D-glucopyranose and 2-amino-2-deoxy- 
$\beta$-D-glucopyranose residues. Chitosan has drawn particular attention as effective biosorbent due to its low cost compared with activated carbon and its high contents of amino and hydroxyl functional groups showing high adsorption potential for various aquatic pollutants. This biopolymer represents an attractive alternative to other biomaterials because of its physico-chemical properties, chemical stability, high reactivity, excellent chelation behavior and high selectivity toward pollutants [1]. Chitosan is a natural polymer which is formed from an easily available chitin and often has better properties than much more expensive synthetic polymers. It is characterized first of all by such valuable properties as bioactivity, i.e. action on living organisms through inhibition or activation of their life processes, biodegradability, i.e. ability to degrade under the influence of natural environmental factors, biocompatibility and biomiscibility, unique sorption and chelating properties for a number of heavy metal ions [2]-[4]. Chitosan was proved to have the best chelating properties among other natural polymers [5]. It is worth noting that among many biopolymers, chitosan has the highest adsorption capacity for metals because amino $\left(\mathrm{NH}_{2}\right)$ and/or hydroxy $(\mathrm{OH})$ groups on chitosan chains serve as coordination sites [6]. So, amino groups are responsible for the uptake of copper cations as follows [7]

$$
\mathrm{NH}_{3}^{+}+\mathrm{Cu}^{2+} \rightarrow \mathrm{NH}_{2} \mathrm{Cu}^{2+}+\mathrm{H}^{+}
$$

Amino groups of chitosan $\mathrm{NH}_{2}$ are responsible for complex formation, in which nitrogen is a donor of electron pairs, although hydroxyl groups- $\mathrm{OH}$ can also participate in sorption. The mechanism of combining these reactive groups with ions of heavy metals is much differentiated and can depend on the ion type, $\mathrm{pH}$ and also the main components of the solution. Great influence on sorptivity has the deacetylation degree of chitosan: the higher it is, the more efficient is the sorption process. The deacetylation degree usually does not exceed 95\%, because production of chitosan with a higher deacetylation degree is very costly.

A wide range of various treatment techniques such as ion exchange, biodegradation, oxidation, solvent extraction and adsorption have been reported to be used for removal of heavy metal ions from industrial effluents. However, adsorption has been widely accepted as one of the most effective pollutant removal processes, with low cost, ease in handling, low consumption of reagents, as well as scope for recovery of value-added components through desorption and regeneration of adsorbent [8]. Copper is one of the essential elements to human body in trace quantities, but at high amounts (over $1.3 \mathrm{mg} / \mathrm{L}$ ) [9]. It has been reported to cause stomach and intestine problems, neurotoxicity, jaundice, and liver toxicity [10]. Moreover, continued inhalation of coppercontaining sprays is linked with an increase in lung cancer among exposed workers which may cause various health problems in liver, kidney, and the central nervous system [11]. Copper $(\mathrm{Cu})$ and some of the other metals ions are of major concern when presenting at higher concentrations in the environment. Their removal has been investigated from water by several researchers using chitosan. McKay et al. investigated the adsorption of some metal ions by chitosan [12]. The adsorption ability of chitin or chitosan to sorb Cu(II) ions from aqueous solutions was studied, taking kinetic, equilibrium and mass transfer aspects into account [13].

\section{Adsorption Isotherm Studies}

The linear form of the isotherms are more frequently used for practical reasons, as they offer the means to determine constants and other parameters describing the adsorption kinetics from experimental. The mathematical correlation is usually depicted by graphs expressing the amount adsorbed on the solid-phase against the residual concentration in solution [14].

\subsection{Langmuir Isotherm}

The Langmuir model assumes that the maximum adsorption takes place in a monolayer of the adsorbate molecules on the adsorbent surface and that all adsorption sites have equivalent energy and negligible interaction between adsorbed molecules [15].

The Langmuir isotherm model used for monolayer adsorption can be represented the following equation.

The Langmuir isotherm was evaluated using the model

$$
\frac{C_{e}}{q_{e}}=\frac{1}{a b}+\frac{C_{e}}{a}
$$

where $C_{e}$ is the equilibrium concentration of metal ions $(\mathrm{mg} / \mathrm{L}), q_{e}$ is the amount of metal ion adsorbed at equilibrium (mg/g), while $a$ is the maximum adsorption capacity of metal ion (mg/g), and $b$ is the Langmuir 
equilibrium constants $(\mathrm{L} / \mathrm{mg})$.

The plot of $\frac{C_{e}}{q_{e}}$ against $C_{e}$ is generated giving a linear plot with a slope of $\frac{1}{a}$ and an intercept of $\frac{1}{a b}$. The essential features of the Langmuir isotherm may be expressed in terms of equilibrium parameter $R_{L}$, which is a dimensionless constant referred to as separation factor or equilibrium parameter

$$
R_{L}=\frac{1}{1+b \cdot C_{0}}
$$

where $C_{0}$ represent the initial concentration of $\mathrm{Cu}^{2+}(\mathrm{mg} / \mathrm{L})$ and $b$ is the Langmuir adsorption equilibrium constant (L/mg). $R_{L}$ value indicates the adsorption nature to be either unfavourable if $R_{L}>1$, linear if $R_{L}=1$, favourable if $0<R_{L}<1$ and irreversible if $R_{L}=0$.

\subsection{The Freundlich Isotherm}

The Freundlich adsorption isotherm, however, is an empirical model and can be used in the case of a heterogeneous surface energy system [16].

$$
q_{e}=K_{F} \cdot C_{e}^{1 / n}
$$

where $C_{e}$ is the equilibrium concentration of metal ion $(\mathrm{mg} / \mathrm{L}), q_{e}$ is the amount of metal ion adsorbed on adsorbent mass unit (mg/g), $K_{F}$ is the maximum adsorption capacity of metal ions $(\mathrm{mg} / \mathrm{g})$ and $n$ is a constant present in non linear-Freundlich isotherm which indicated the adsorption intensity. The linearized form of Freundlich equation is stated below

$$
\ln q_{e}=\frac{1}{n} \ln C_{e}+\ln K_{F}
$$

where the factor $1 / n$ is usually which represent the slope of the strait line graph obtained by plotting $\ln q_{e}$ against $\ln C_{e}$. The value of $1 / n$ should be between 0 and 1 , if the process of adsorption is describe by chemisorptions.

\subsection{The Elovich Isotherm}

The Elovich isotherm assumes that the adsorption sites multiply exponentially with adsorption, indicating multilayer adsorption. The Elovich equation is express as follows [17]

$$
\frac{q_{e}}{Q_{m}}=K_{E} C_{e}^{-q_{e} / Q_{m}}
$$

where $K_{E}$ is the Elovich equilibrium constant $(\mathrm{L} / \mathrm{mg})$ and $Q_{m}$ is the Elovich maximum adsorption capacity (mg/g). The linearized form of the Elovich equation used to plot $\ln q_{e} / C_{e}$ versus $q_{e}$

$$
\ln \frac{q_{e}}{C_{e}}=\ln \left(K_{E} q_{m}\right)-\frac{1}{q_{m}} q_{e}
$$

\subsection{Dubinin-Radushkevich Isotherm}

The Dubinin-Radushkevich isotherm equation, which is more generally used to distinguish between physical and chemical adsorption, is given by the following equation

$$
\ln Q_{e}=K \varepsilon^{2}+\ln B_{\mathrm{DR}}
$$

where $Q_{e}$ is the amount of metal ions adsorbed (mg/g), $B_{\mathrm{DR}}$ is the maximum adsorption capacity of metal ions ( $\mathrm{mg} / \mathrm{g}), K$ is the Dubinin-Radushkevich constant $\left(\mathrm{kJ}^{2} / \mathrm{mol}\right)$ and $\varepsilon$ is Polanyi potential given below

$$
\varepsilon=R T \ln \left(1+\frac{1}{C_{e}}\right)
$$


where $R$ is the gas constant in $\mathrm{J} \cdot(\mathrm{Kmol})^{-1}, T$ is the temperature in Kelvin and $C_{e}$ is the equilibrium concentration of metal ions $(\mathrm{mg} / \mathrm{L})$. Thus the plot of $\ln Q_{e}$ against $\varepsilon^{2}$ gives a straight line with a slope of $K$ and an intercept of $B_{\mathrm{DR}}$. The Dubinin-Radushkevich constant can give the valuable information regarding the mean energy of adsorption by the following equation

$$
E=\frac{1}{\sqrt{2 B_{\mathrm{DR}}}}
$$

where $E$ is the mean adsorption energy $(\mathrm{kJ} / \mathrm{mol})$, and $K$ is the Dubinin-Radushkevich constant.

\subsection{The Temkin Isotherm}

This isotherm contains a factor that explicitly taking into the account of adsorbent-adsorbate interactions. By ignoring the extremely low and large value of concentrations, the model assumes that heat of adsorption (function of temperature) of all molecules in the layer would decrease linearly rather than logarithmic with coverage [18] [19]. As implied in the equation, its derivation is characterized by a uniform distribution of binding energies (up to some maximum binding energy) was carried out by plotting the quantity sorbed $q_{e}$ against $\ln C_{e}$ and the constants were determined from the slope and intercept. The model is given by the following equation

$$
\begin{gathered}
q_{e}=\frac{R T}{b} \ln \left(A_{T} C_{e}\right) \\
q_{e}=\frac{R T}{b} \ln A_{T}+\frac{R T}{b} \ln C_{e} \\
B=\frac{R T}{b_{T}} \\
q_{e}=B \ln A_{T}+B \ln C_{e}
\end{gathered}
$$

$A_{T}=$ Temkin isotherm equilibrium binding constant (L/g);

$b_{T}=$ Temkin isotherm constant;

$R=$ universal gas constant $(8.314 \mathrm{~J} / \mathrm{mol} / \mathrm{K})$;

$T=$ temperature at $298 \mathrm{~K}$;

$B=$ constant related to heat of sorption $(\mathrm{J} / \mathrm{mol})$.

\subsection{Adsorption Kinetics}

In order to evaluate the mechanism of adsorption and the potential steps controlling the rate of adsorption, the basic characteristics of a good adsorbent considering adsorption kinetics under constant temperature and optimum solution $\mathrm{pH}$, were determined, by using various initial metal ion concentrations. The kinetics of adsorption was determined by analyzing adsorptive uptake of heavy metals from the prepared copper (II) ion at different time intervals. The pseudo-first-order and pseudo-second-order kinetic models were applied to the experimental data to predict the adsorption kinetics onto chitosan. The linearity of each model when plotted indicates whether the model suitably described the adsorption process or not. The pseudo-first-order equation is generally expressed as shown in equation below [20].

$$
\log \left(q_{e}-q_{t}\right)=\log q_{e}-\frac{k_{1}}{2.303} t
$$

where $q_{e}$ is the amount of $\mathrm{Cu}(\mathrm{II})$ ion adsorbed $\left(\mathrm{mg} / \mathrm{g}\right.$ ) at equilibrium, $q_{t}$ is the amount of $\mathrm{Cu}(\mathrm{II})$ ion adsorbed on adsorbent mass unit $(\mathrm{mg} / \mathrm{g})$ at time $t$ and $k_{1}$ is the rate constant of the first order adsorption reaction $\left(\min ^{-1}\right)$. In order to determine the value of $k_{1}$, the $\log \left(q_{e}-q_{t}\right)$ versus $\log q_{e}$ is plot was used [17].

The pseudo-second-order equation model is given below is

$$
\frac{t}{q_{t}}=\frac{1}{k_{2} q_{e}^{2}}+\frac{t}{q_{e}}
$$

where $q_{e}$ is the amount of $\mathrm{Cu}(\mathrm{II})$ ion adsorbed (mg/g) at equilibrium, $q_{t}$ is the amount of $\mathrm{Cu}(\mathrm{II})$ ion adsorbed 
on adsorbent mass unit (mg/g) at time $t$ and $k_{2}$ is the rate constant of the second order adsorption reaction $\left(\mathrm{g} \cdot \mathrm{mg}^{-1} \cdot \mathrm{min}^{-1}\right)$. In order to determined the value of $k_{2}, \frac{t}{q_{t}}$ versus $t$ plot is used [20].

\section{Materials and Methods}

Chitosan with a degree of deacetylation about approximately 70\% was obtained from Sigma Aldrich Germany, Sodium hydroxide $(\mathrm{NaOH})$, Hydrochloric acid $(\mathrm{HCl})$ and copper (II) suplhate pentahydrate all reagent used were of analytical grade. Deionized and distill water was used to prepared all reagents. Crab shells were obtained from Lagos (Nigeria) Lagoon waters (osa) and was used to synthesized the local chitosan with degree of deacétylation of $71 \%$.

\subsection{Production of Chitosan}

Isolation of chitosan from crab shell wastes involves four traditional steps deproteinization (DP), demineralization (DM), decolorization (DC), and deacetylation (DA). The wet crab is washed and dried follow by grinding and sieving to reduced the surface area, the grinded crab is then stored in a plastic bottle. The crab shell was place in a solution of $3.5 \% \mathrm{NaOH}(w / v)$ for $2 \mathrm{~h}$ at $65^{\circ} \mathrm{C}$, solid:solvent $(1: 10, w / v)$. Later, the solid was separated from the liquid and washed with soft water the solid was placed in $1 \mathrm{~N} \mathrm{HCl}$ for $30 \mathrm{~min}$ at room temperature, solid:solvent $(1: 15, w / v)$. Subsequently, the liquid was removed and the solid was washed with soft water. $0.315 \%$ sodium hypochlorite $(\mathrm{NaOCl})(w / v)$ for $5 \mathrm{~min}$ at room temp. solid:solvent $(1: 10, \mathrm{w} / \mathrm{v})$ was poured into the vessel containing the solid and the suspension was agitated until the pigmentation of the solid disappeared. The white solid (chitin) was washed and dried in an oven. the deacetylation of chitn was carried out by mixing chitin with $50 \% \mathrm{NaOH}$ for $30 \mathrm{~min}$ at $115 \mathrm{psi} / 121^{\circ} \mathrm{C}$, solid:solvent $(1: 10, w / v)$ The mixture was washed with soft water several times to remove residual sodium hydroxide, until $\mathrm{pH} 7$ was achieved. The material was dried in an oven at $50^{\circ} \mathrm{C}$.

\subsection{Batch Adsorption Studies}

Batch adsorption studies were carried out at room temperature using a conical flasks with $50 \mathrm{~mL}$ of the working $\mathrm{Cu}(\mathrm{II})$ ion solution of different concentrations and stirrers at $300 \mathrm{rpm}$ in view of the results from previous work [21]. The $\mathrm{pH}$ of each solution was adjusted by adding either dilute $\mathrm{NaOH}$ or HCL solution, initial $\mathrm{Cu}(\mathrm{II})$ concentration, contact time, and adsorbent dose were evaluated during the present study. Samples were collected from the flasks at predetermined time intervals for analyzing the residual $\mathrm{Cu}(\mathrm{II})$ concentration in the solution. The adsorbate was removed by filtration through Whatmann filter paper no 3. The residual concentration of $\mathrm{Cu}(\mathrm{II})$ in the supernatant solution was determined by atomic absorption spectroscopy (AAS).

The experiments were performed in duplicates and the amount of $\mathrm{Cu}(\mathrm{II})$ ions adsorbed in milligram per gram was determined by using the following mass balance equation

$$
q_{e}=\frac{\left(C_{o}-C_{e}\right) \cdot V}{m}
$$

In which, $C_{o}$ and $C_{e}$ are $\mathrm{Cu}(\mathrm{II})$ concentrations $(\mathrm{mg} / \mathrm{L})$ before and after adsorption, respectively, $V$ is the volume of adsorbate in liter and $\mathrm{m}$ is the weight of the adsorbent in grams. The percentage of removal of $\mathrm{Cu}(\mathrm{II})$ ions was calculated from the following equation:

$$
\text { Removal }(\%)=\frac{C_{o}-C_{e}}{C_{o}} \times 100
$$

\subsection{Preparation of Copper Stock Solution}

Copper (II) sulphate pentahydrate $\left(\mathrm{CuSO}_{4} \cdot 5 \mathrm{H}_{2} \mathrm{O}\right)$ analar grade is used as the source for copper stock solution. The solution is prepared with di ionized water the copper (II) stock solution (1000 mg/L) was made by dissolving $3.916 \mathrm{~g}$ of $99 \% \mathrm{CuSO}_{4} \cdot 5 \mathrm{H}_{2} \mathrm{O}$ in one liter di ionized water. Samples of different concentrations of copper (II) are prepared from this stock solution. 


\section{Result and Discussion}

\subsection{Characterization of Chitosan}

The concentrations of metal ions were measured using an atomic absorption spectrophotometer (Varian AA 240). All reported copper concentrations are the mean value of three replicates.

\subsubsection{FTIR}

FTIR analysis was used to characterize the surface chemistry of chitosan before adsorption of copper. FTIR analysis was used to identify the type of functional groups on the adsorbent surface peaks at $3500-3100 \mathrm{~cm}^{-1}$ related to $\mathrm{N}-\mathrm{H}$ and $\mathrm{C}-\mathrm{N}$ valent vibrations and at $3400 \mathrm{~cm}^{-1}$ related to symmetrical valent vibration of free $\mathrm{NH}_{2}$ and $\mathrm{OH}$ group for Figure 1 and Figure 2.

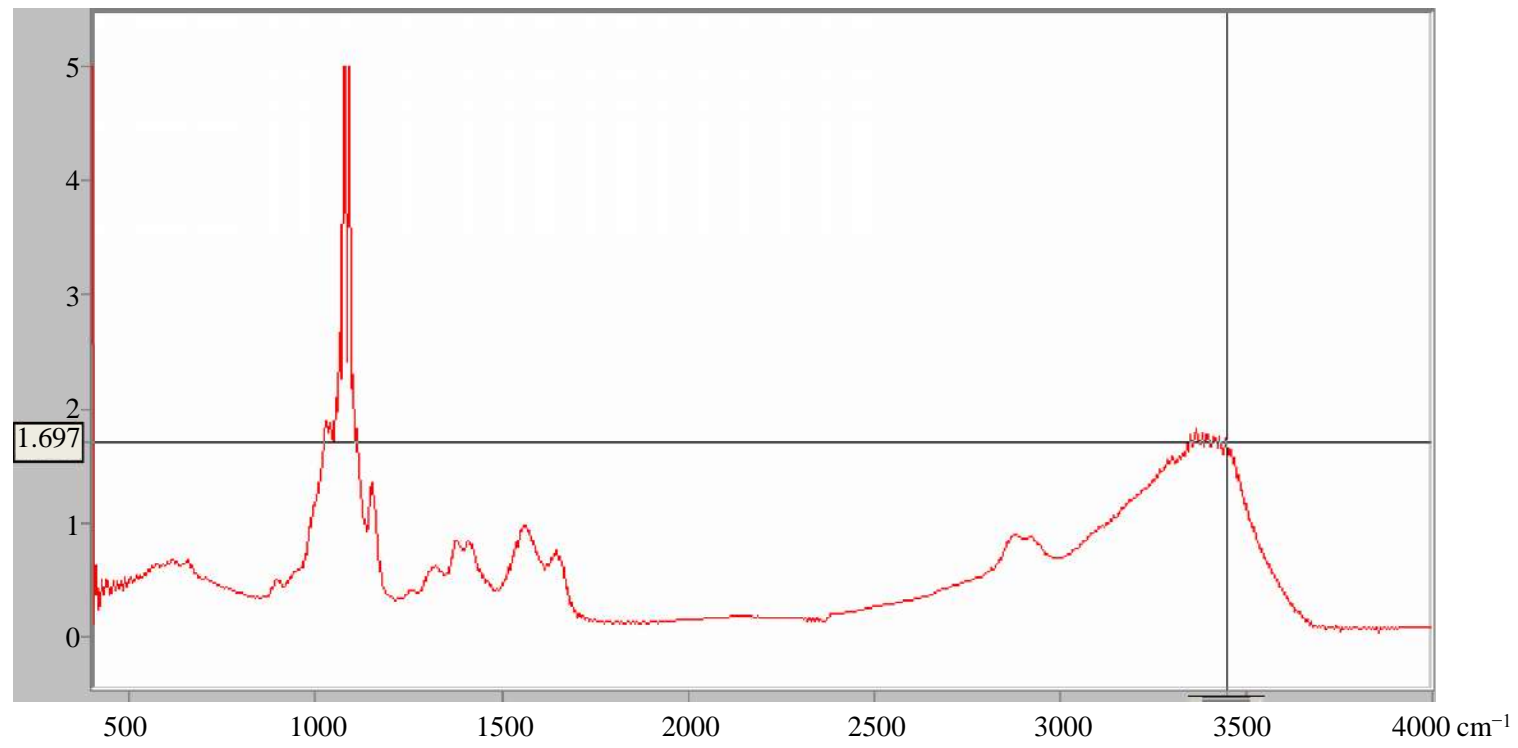

$\mathrm{A}_{1655}=0.73, \mathrm{~A}_{3450}=1.697, \mathrm{DD}=68 \%$.

Figure 1. FTIR commercial chitosan.

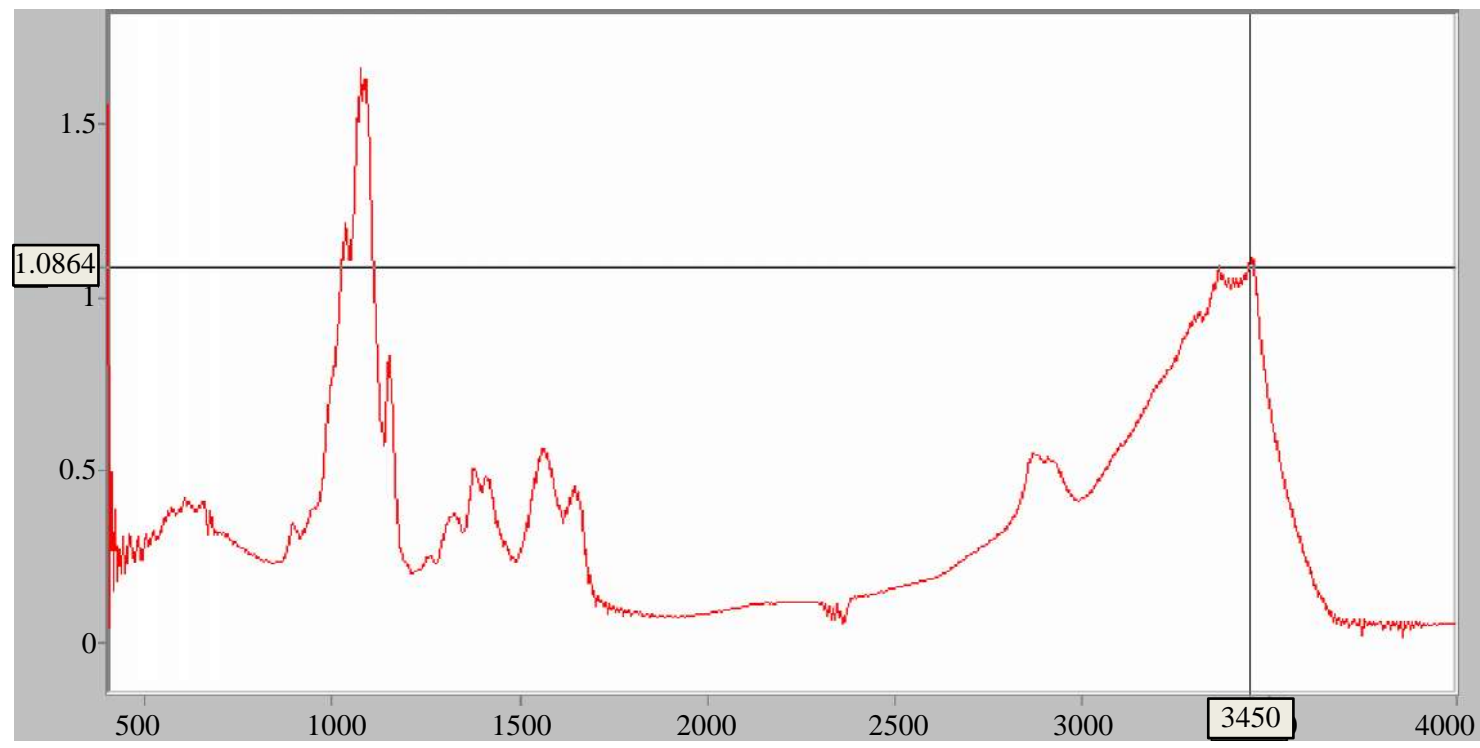

$\mathrm{A}_{1655}=0.419, \mathrm{~A}_{3450}=1.086, \mathrm{DD}=71 \%$.

Figure 2. FTIR of locally developed chitosan. 
The degree of deacetylation (DD) of the chitosan was calculated using the baseline by Domszy and Roberts (1985). The computation equation for the baseline is given below:

$$
\mathrm{DD}=100-\left[\left(\frac{\mathrm{A}_{1655}}{\mathrm{~A}_{3450}}\right) \times 100 / 1.33\right]
$$

Figure 1 is the FTIR of commercial chitosan the DD was calculated using Equation (19).

Figure 2 is the FTIR of locally developed chitosan the DD was calculated using Equation (19), it is observed that the local developed chitosan has high absorbance as compare to commercial chitosan. The result was compared with commercial chitosan and a significant degree of similarities was observed.

\subsubsection{Scanning Electronic Machine (SEM)}

The SEM micrograph of chitosan powder of four different magnifications. The morphology has globules of crystalline structure with smooth surface. As it was prepared as fine ground powder, the morphology shows that the specimen is in particle structures. In a study [22], the morphology of chitosan was described as microfibrillar crystalline structure with large portion of surface structure.

Figure 3 shows the morphology structure of commercial chitosan at four different magnifications.

Figure 4 shows the morphological structure of locally developed chitosan at four different magnifications.
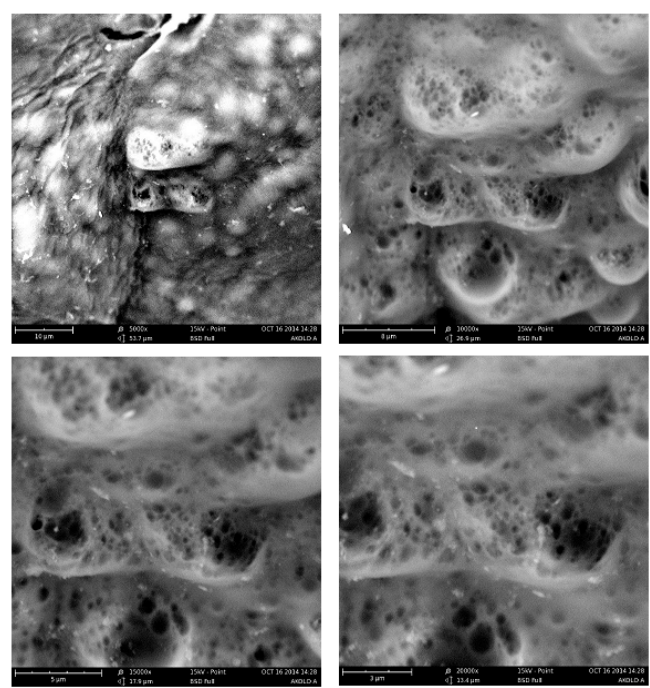

Figure 3. SEM image of commercial chitosan.
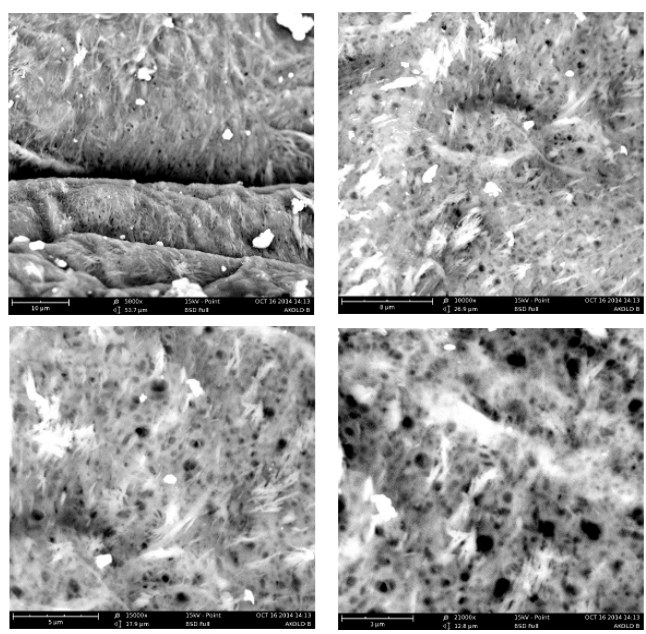

Figure 4. SEM image of locally developed chitosan. 


\subsubsection{Electron Dispersive Spectroscopy (EDS)}

Electron Dispersive Spectroscopy (EDS) is a test to examine the presence of elements through amplitude of wavelength for the $x$-ray emitted after the electron was hit by the electron beam. For the emission of $x$-ray, the atoms must contain minimum of $K$-shell and $L$-shell where the electron is allow to dislodge from shell to shell. Therefore, hydrogen being the only elements in the periodic table with only $K$ shell is not detectable with EDS [22]-[24].

Figure 5 is the EDX spectrum for commercial chitosan which shows the major elements in the structure of chitosan which are active sites for adsorption and Table 1 shows the weight percent of the element. The EDS spectrum of commercial chitosan revealed N (40.3 wt\%), C (31.6 wt\%), and O (28.1 wt\%), as major components.

Figure 6 is the EDX spectrum for locally develop chitosan which shows the functional group in the structure of chitosan which are active sites for adsorption and Table 2 shows the weight percent of the element. There is great similarity between the spectrum represented in Figure 5 and Figure 6.

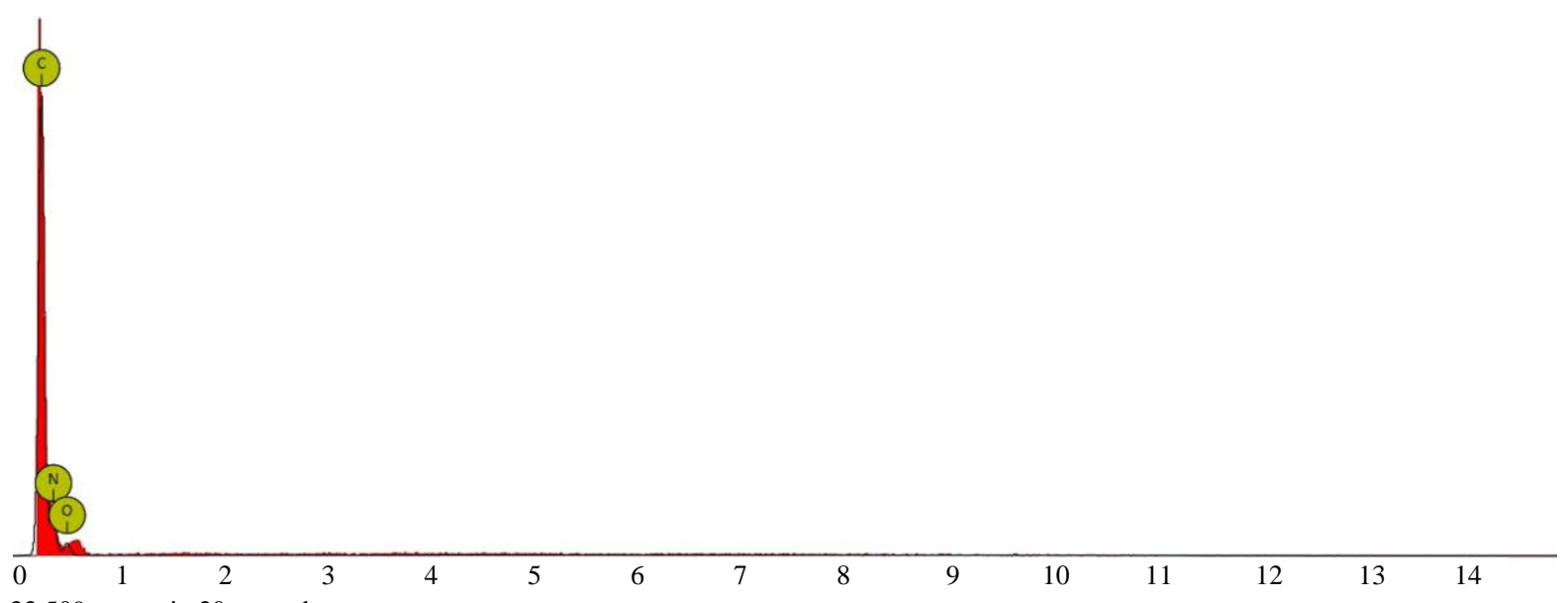

33,509 counts in 30 seconds

Figure 5. EDS spectrums for commercial chitosan.

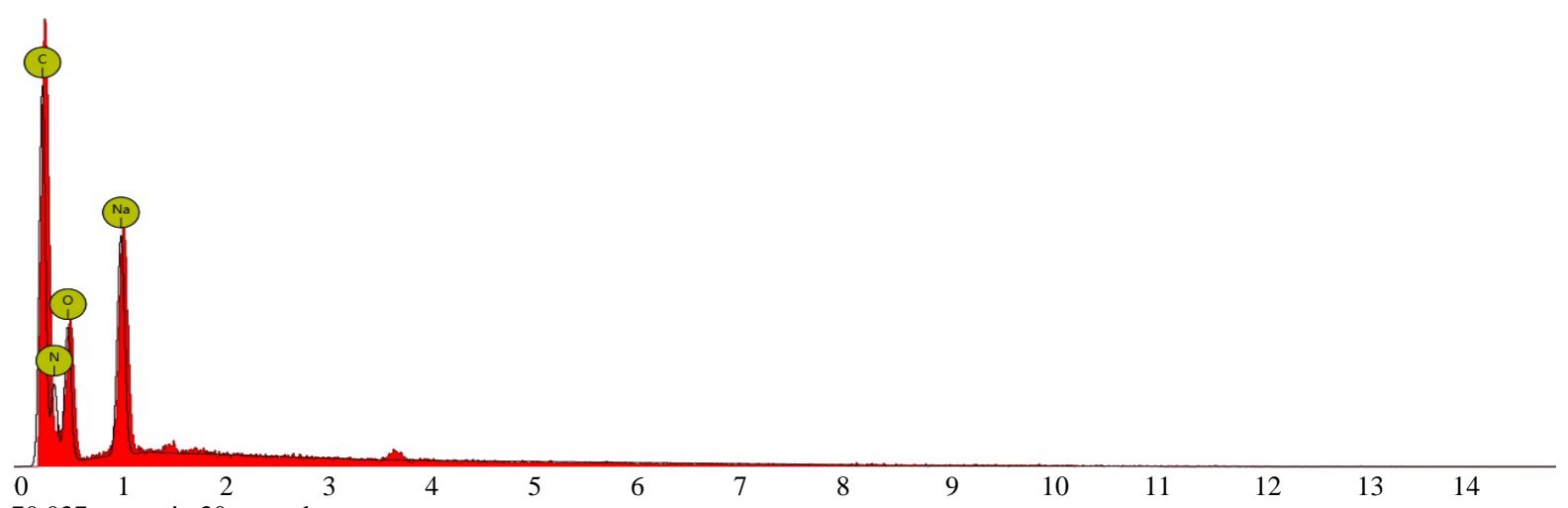

70,037 counts in 30 seconds

Figure 6. EDS spectrum for locally developed chitosan.

Table 1. Elemental weight composition of commercial chitosan.

\begin{tabular}{ccccccc}
\hline Atomic number & Element symbol & Element name & $\begin{array}{c}\text { Confidence } \\
\text { level }\end{array}$ & $\begin{array}{c}\text { Concentration } \\
\text { percentage }\end{array}$ & $\begin{array}{c}\text { Certainty } \\
\text { percentage } \\
\text { percentage }\end{array}$ \\
\hline 7 & $\mathrm{~N}$ & Nitrogen & 100 & 40.3 & 97.5 & 2.5 \\
6 & $\mathrm{C}$ & Carbon & 100 & 31.6 & 99.3 \\
8 & $\mathrm{O}$ & Oxygen & 100 & 28.1 & 95.4 \\
\hline
\end{tabular}


Table 2. Elemental weight composition for locally developed chitosan.

\begin{tabular}{ccccccc}
\hline $\begin{array}{c}\text { Atomic } \\
\text { number }\end{array}$ & $\begin{array}{c}\text { Element } \\
\text { symbol }\end{array}$ & Element name & $\begin{array}{c}\text { Confidence } \\
\text { level }\end{array}$ & $\begin{array}{c}\text { Concentration } \\
\text { percentage }\end{array}$ & $\begin{array}{c}\text { Certainty } \\
\text { percentage }\end{array}$ & $\begin{array}{c}\text { Error } \\
\text { percentage }\end{array}$ \\
\hline 8 & $\mathrm{O}$ & Oxygen & 100 & 39.6 & 98.4 & 1.6 \\
11 & $\mathrm{Na}$ & Sodium & 100 & 32 & 98.8 & 1.2 \\
6 & $\mathrm{C}$ & Carbon & 100 & 14.9 & 99.1 & 0.9 \\
7 & $\mathrm{~N}$ & Nitrogen & 100 & 13.5 & 97.8 & 2.2 \\
\hline
\end{tabular}

\subsection{Comparative Study between Commercial Chitosan and Locally Developed Chitosan}

The effect of concentration at room temperature at $\mathrm{P}_{\mathrm{H}}=6$, and dosage $1 \mathrm{~g}$ on both locally develop and commercial chitosan.

Table 3 shows the percentage removal of commercial chitosan against time at various intervals.

The graph of Figure 7 shows the percentage removal of commercial chitosan against contact time.

Table 4 shows the percentage removal of locally develop chitosan against time at various interval.

The graph of Figure 8 shows the percentage removal of locally develop against contact time.

The contact time represents the time necessary for the adsorption process to reach equilibrium. For each sample the adsorption capacity was studied as a function of time. The contact time was varied from 30 to 90 minutes. The effect was studied at room temperature while stirring at $300 \mathrm{rpm}$ using a constant adsorbent dose of $1 \mathrm{~g}$. The adsorption reached equilibrium at short contact time for both commercial and locally develop chitosan, which was due to the availability of active sites on the adsorbent surface. As the active sites were occupied, adsorption slowed down and finally an equilibrium stage was reached.

Langmuir isotherm model of copper (II) onto commercial and locally developed chitosan

The linearized form of Equation (2) (Langmuir isotherm) was plot in Figure $9 C_{e} / q$ against $C_{e}$ for commercial chitosan. The plot is highly correlated and the Langmuir constants are determined using the intercept and the slope of the graph which is summarized in Table 5.

The linearized form of Equation (2) (Langmuir isotherm) was plot in Figure $10 C_{e} / q$ against $C_{e}$ for locally develop chitosan. The plot is highly correlated and the Langmuir constants are determined using the intercept and the slope of the graph which is summarized in Table 5.

Elovich Isotherm for copper (II) onto commercial and local developed chitosan (Figure 11)

The linearized form of the Elovich isotherm Equation (7) was used to plot $\ln \left(q_{e} / C_{e}\right)$ versus $q_{e}$ for commercial chitosan (Figure 12).

The elovich constant terms are summarized in Table 6.

The linearized form of the Elovich isotherm Equation (7) was used to plot $\ln \left(q_{e} / C_{e}\right)$ versus $q_{e}$ for locally developed chitosan. The Elovich constant terms are summarized in Table 6.

\section{Temkin Isotherm}

The linearized form of Temkin isotherm model Equation (12) is plotted for commercial chitosan in Figure 13 and the Temkin constants are summarized in Table 7.

The linearized form of Temkin isotherm model Equation (12) is plotted for locally developed chitosan in Figure 14 and the Temkin constants are summarized in Table 7.

\section{Freundlich Isotherm}

The linearized form of Freundlich isotherm Equation (5) is plotted in Figure 15 for commercial chitosan. The freundlich constants are summarized in Table 8.

The linearized form of Freundlich isotherm Equation (5) is plotted in Figure 16 for locally developed chitosan. The freundlich constants are summarized in Table 8.

Dubinin-Radushkevich Isotherm for locally developed chitosan

Dubinin-Radushkevich model constants of Table 9 give the valuable information regarding the mean energy of adsorption $\mathrm{E}(\mathrm{kJ} / \mathrm{mol})$ and the Dubinin-Radushkevich constant $\left(\mathrm{K}_{\mathrm{ad}}\right)$.

Equilibrium isotherm are essential for describing the mechanism of adsorption for The equilibrium data of $\mathrm{Cu}^{2+}$ ion were subjected to five different adsorption isotherm models: Langmuir, Elovich, Temkin, Freundlich and Dubinin-Radushkevich are summarized in Table 5 to Table 9 respectively. The Langmuir and Freudlich isotherm model predict the adsorption data better than Elovich and Temkin because high correlation coefficients 
Table 3. Effect of contact time for commercial chitosan.

\begin{tabular}{ccccc}
\hline Runs & Time (mins) & $\mathrm{C}_{\mathrm{o}}(\mathrm{mg} / \mathrm{L})$ & $\mathrm{C}_{\mathrm{e}}(\mathrm{mg} / \mathrm{L})$ & \% Removal \\
\hline 1 & 30 & 30 & 0.15 & 99.5 \\
2 & 45 & 30 & 0.06 & 99.8 \\
3 & 60 & 30 & 0.1 & 96.67 \\
4 & 75 & 30 & 0.07 & 99.77 \\
\hline
\end{tabular}

Table 4. Effect of contact time on local chitosan.

\begin{tabular}{ccccc}
\hline Runs & Time (mins) & $\mathrm{C}_{\mathrm{o}}(\mathrm{mg} / \mathrm{L})$ & $\mathrm{C}_{\mathrm{e}}(\mathrm{mg} / \mathrm{L})$ & \% Removal \\
\hline 1 & 30 & 30 & 0.53 & 98.23 \\
2 & 45 & 30 & 0.55 & 98.17 \\
3 & 60 & 30 & 0.61 & 97.97 \\
4 & 75 & 30 & 0.58 & 98.07 \\
\hline
\end{tabular}

Table 5. Langmuir model coefficient.

\begin{tabular}{ccccc}
\hline \multirow{2}{*}{ Adsorbent } & \multicolumn{2}{c}{ Adsorbent constants } & & $\mathrm{R}^{2}$ \\
\cline { 2 - 4 } & $\mathrm{a}(\mathrm{mg} / \mathrm{g})$ & $\mathrm{b}(\mathrm{L} / \mathrm{mg})$ & 0 & 0.9999 \\
C Chitosan & 1.49 & 3728.56 & 0.000361 & 0.9999 \\
\hline
\end{tabular}

Table 6. Elovich isotherm coefficient.

\begin{tabular}{cccc}
\hline Adsorbent & \multicolumn{3}{c}{ Adsorbent constants } \\
\cline { 2 - 4 } & $\mathrm{Q}_{\mathrm{m}}(\mathrm{mg} / \mathrm{g})$ & $\mathrm{K}_{\mathrm{E}}(\mathrm{L} / \mathrm{mg})$ & $\mathrm{R}^{2}$ \\
\hline C Chitosan & 0.00502 & 0 & 0.9915 \\
L Chitosan & 0.0301 & 0.0000 & 0.9006 \\
\hline
\end{tabular}

Table 7. Temkin isotherm.

\begin{tabular}{ccccc}
\hline Adsorbent & $\mathrm{A}_{\mathrm{T}}(\mathrm{L} / \mathrm{g})$ & $\mathrm{b}_{\mathrm{T}}$ & $\mathrm{B}$ & $\mathrm{R}^{2}$ \\
\hline C Chitosan & 4.41 & 500519.6 & 0.00495 & 0.983 \\
L Chitosan & 4.297 & 99580 & 0.02488 & 0.81 \\
\hline
\end{tabular}

Table 8. Freundlich isotherm coefficients.

\begin{tabular}{ccccc}
\hline & $1 / \mathrm{n}$ & $\mathrm{n}$ & $\mathrm{K}_{\mathrm{F}}(\mathrm{mg} / \mathrm{g})$ & $\mathrm{R}^{2}$ \\
\hline C Chitosan & 0.003 & 333.33 & 1.48 & 0.985 \\
L Chitosan & 0.008 & 125 & 1.45 & 0.998 \\
\hline
\end{tabular}

Table 9. Dubinin-Radushkevichs model constants.

\begin{tabular}{cccc}
\hline Adsorbent & $\mathrm{K}_{\mathrm{ad}}\left(\mathrm{mol}^{2} / \mathrm{kJ}^{2}\right)$ & $\mathrm{E}(\mathrm{kJ} / \mathrm{mol})$ & $\mathrm{R}^{2}$ \\
\hline Local Chitosan & $2.290 \times 10^{-9}$ & 0.59 & 0.9901 \\
\hline
\end{tabular}




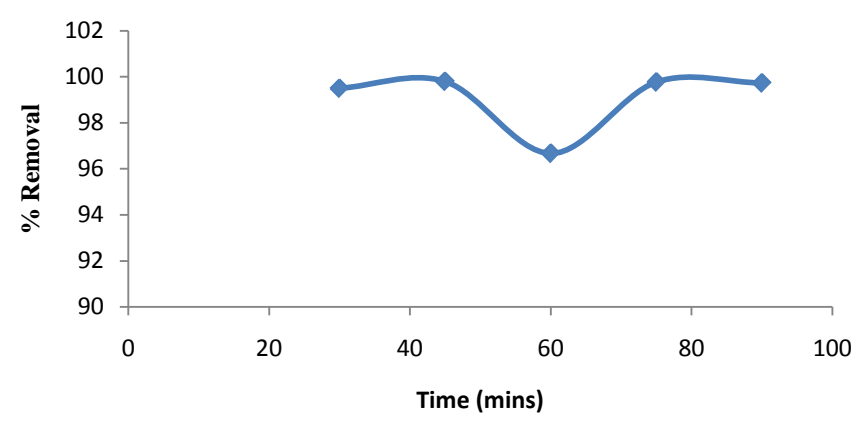

Figure 7. Effect of contact time on the adsorption of $\mathrm{Cu}(\mathrm{II})$ by commercial chitosan.

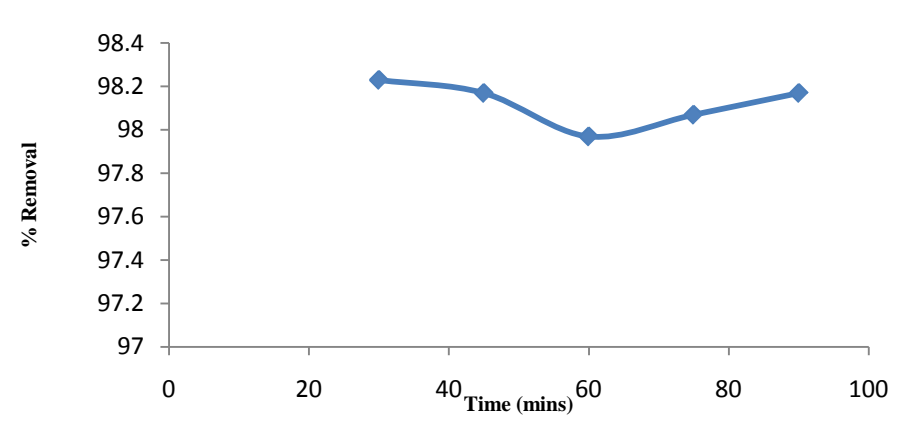

Figure 8. Effect of contact time on the adsorption $\mathrm{Cu}(\mathrm{II})$ by locally developed chitosan.

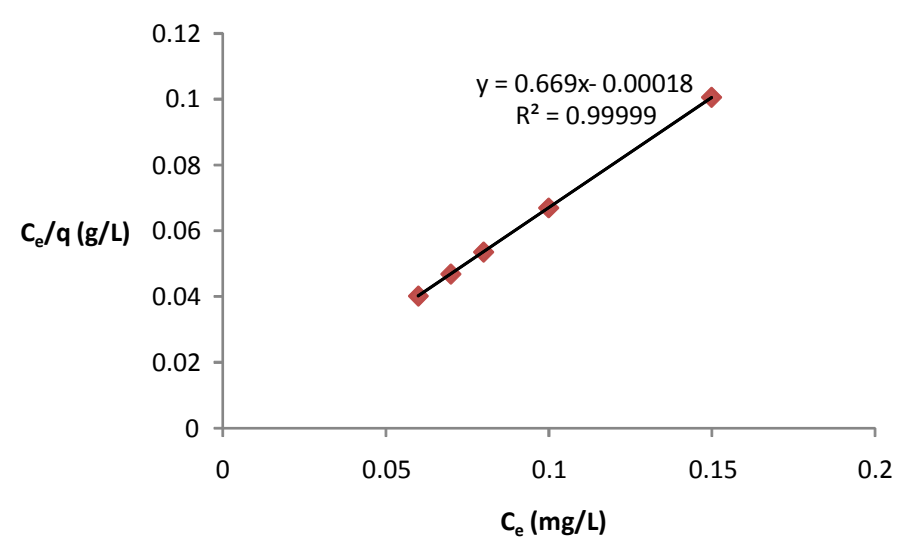

Figure 9. Langmuir isotherm of commercial chitosan onto $\mathrm{Cu}^{2+}$ ion.

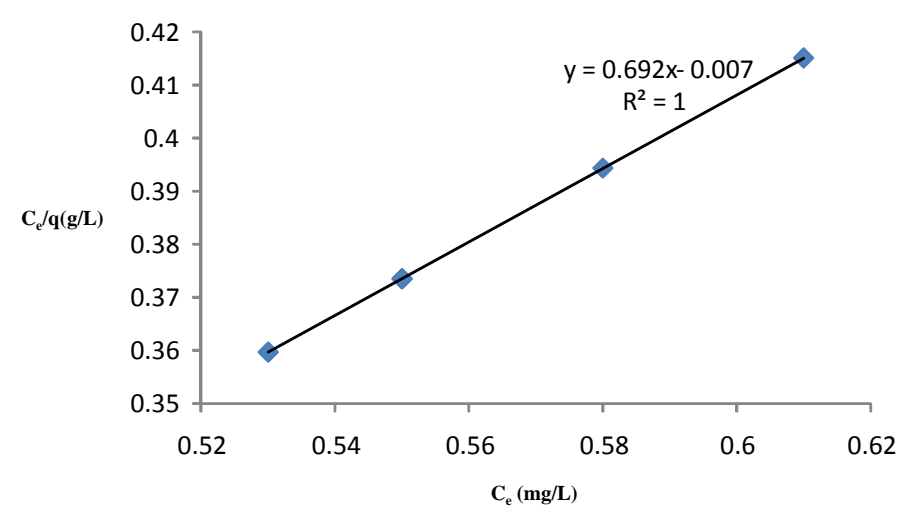

Figure 10. Langmuir isotherm of locally developed chitosan onto $\mathrm{Cu}^{2+}$. 
$\left(R^{2}>0.99\right)$ were obtained at a higher confidence level. The Freundlich constants $K_{F}$ and $1 / n$ of for $\mathrm{Cu}^{2+}$ were found to be $1.49 \mathrm{mg} / \mathrm{g}$ and 0.003 respectively for commercial chitosan and $1.45 \mathrm{mg} / \mathrm{g}$ and $0.008 \mathrm{respec}-$ tively for local chitosan (Table 8). The values of $1 / n$ are between 0 than 1 for both the adsorbents, which indicate normal adsorption. The low $1 / n$ in Table 8 suggested that any large change in the equilibrium concentration $\mathrm{Cu}^{2+}$ ions would not result in a change in the amount of $\mathrm{Cu}^{2+}$ sorbed by the chitosan. According to the values of the correlation coefficient $\left(R^{2}\right)$ from Figure 9 to Figure 17, the best-fit isotherm model was the Langmuir isotherm (Figure 9 and Figure 10) model follow by the Freundlich isotherm Figure 15 and Figure 16 model. The Elovich modeling of the experimental data of Figure 11 and Figure 12 also indicate chemisorptions took place (Mclintock, 1967). High correlation coefficients were observed when the data were fitted to this model especially for the commercial chitosan in Table 6 suggested that the adsorption of $\mathrm{Cu}^{2+}$ occurred by chemisorptions. The Temkim model of Figure 13 and Figure 14 respectively had the lowest value of correlation coefficient, which suggested that this model was not the best descriptor of $\mathrm{Cu}^{2+}$ ion adsorption onto local and commercial chitosan. However, the model did indicate that $\mathrm{Cu}^{2+}$ is an exothermic process, since $B>0$ for both adsorbents. Dubinin-Rasdushkevich isotherm model of Figure 17 only describe the locally developed chitosan with high correlation of coefficient $\left(R^{2}>0.99\right)$.

\section{Adsorption Kinetics}

Pseudo-first-order (Lagergren model) for adsorption of $\mathrm{Cu}(\mathrm{II})$ onto chitosan (Figure 18 and Figure 19).

Pseudo-second-order reaction model for adsorption of $\mathrm{Cu}^{2+}$ ion on chitosan (Figure 20).

The data on the dependence of adsorption capacity on time were used for kinetic analysis. Figures 18-21 show the tests of pseudo-first-order rate equation (Lagergren Model), and pseudo-second-order rate equation (Ho Model) respectively. The results of the fitted data, in Figure 20 and Figure 21, show that pseudo-secondorder reaction model [25] yield very good straight lines compared to the pseudo-first-order reaction model Figure 18 and Figure 19, which is significantly scattered (non linear). Also the theoretical (calculated) value of $q_{e}$ of, pseudo-second-order reaction model, are closer to the experimental value of $q_{e}$. for instance the calculated value of $\mathrm{Cu}^{2+}$ onto local chitosan was $1.4728 \mathrm{mg} \cdot \mathrm{g}^{-1}$ which is in closed agreement with the experimental value of $1.4735 \mathrm{mg} \cdot \mathrm{g}^{-1}$ compared to $\mathrm{Cu}^{2+}$ of pseudo-first-order reaction model, with calculated valued of 0.1042 $\mathrm{mg} \cdot \mathrm{g}^{-1}$ which differ greatly from the experimental value of $1.4735 \mathrm{mg} \cdot \mathrm{g}^{-1}$. Also the calculated value of $\mathrm{Cu}^{2+}$ onto commercial chitosan was $1.4993 \mathrm{mg} \cdot \mathrm{g}^{-1}$ which is in closed agreement with the experimental value of $1.4965 \mathrm{mg} \cdot \mathrm{g}^{-1}$ compared to $\mathrm{Cu}^{2+}$ of pseudo-first-order reaction model, with calculated valued of $1.096 \mathrm{mg} \cdot \mathrm{g}^{-1}$ which differ greatly from the experimental value of $1.4735 \mathrm{mg} \cdot \mathrm{g}^{-1}$ these fact suggest that the adsorption of $\mathrm{Cu}^{2+}$ by commercial and locally produced chitosan from crab shells follows the pseudo-second-order reaction model which rely on the assumption that chemisorptions may be the rate-limiting step. In chemisorptions the heavy metals stick to the adsorbent surface by forming a chemical usually covalent bond and tend to find sites that maximize their coordination with the surface [26].

Coefficient of empirical kinetic models for local and commercial chitosan from crab shell

Table 10 shows the experimental and the calculated value of $q_{e}$ for pseudo-first-order and pseudo-second-order reaction model of both adsorbent.

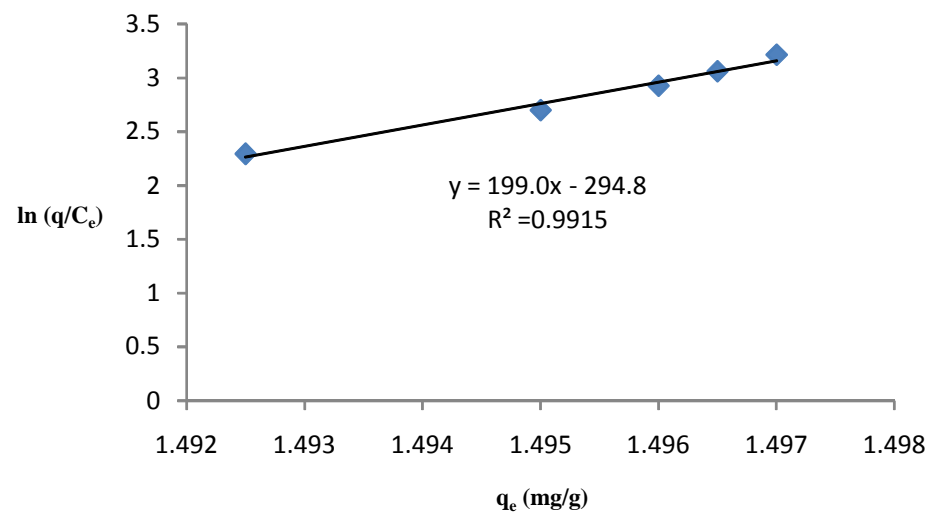

Figure 11. Elovich isotherm of $\mathrm{Cu}(\mathrm{II})$ onto commercial chitosan. 


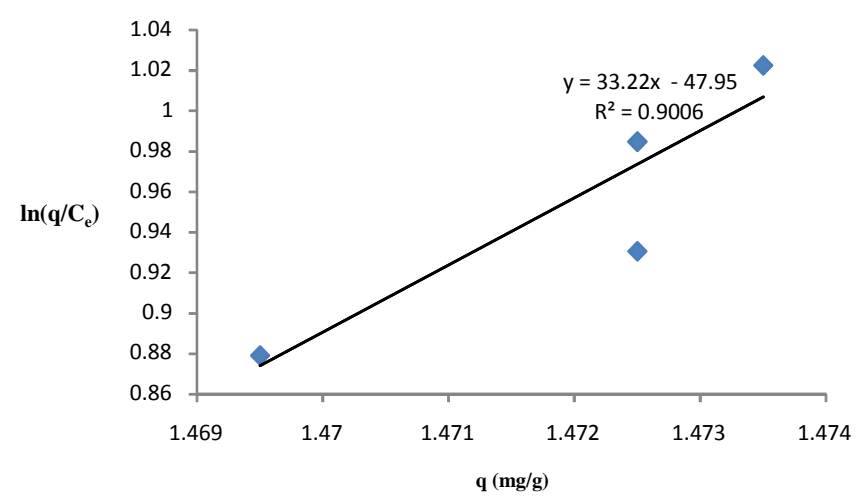

Figure 12. $\mathrm{Cu}(\mathrm{II})$ onto locally developed chitosan.

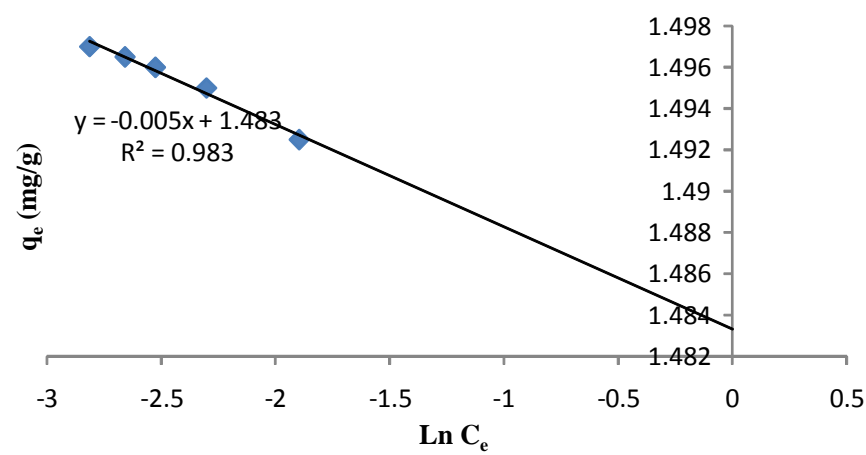

Figure 13. Temkin isotherm of $\mathrm{Cu}(\mathrm{II})$ onto commercial chitosan.

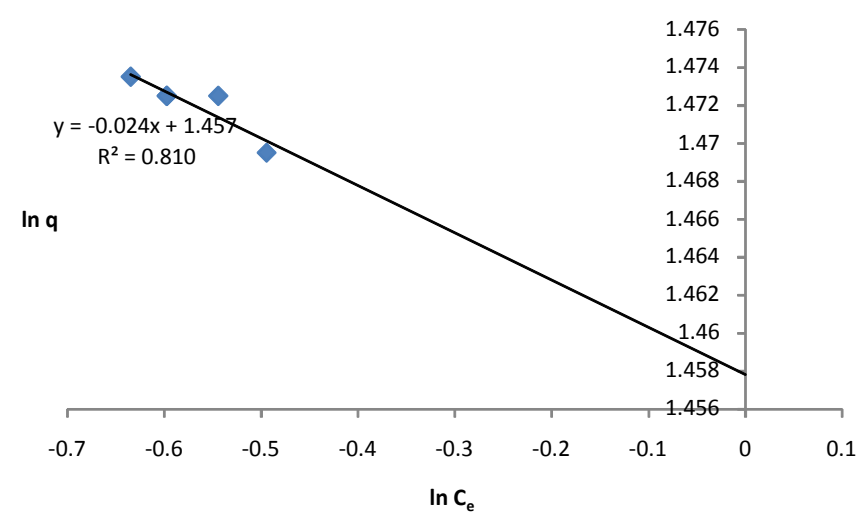

Figure 14. Temkin isotherm of $\mathrm{Cu}(\mathrm{II})$ onto local chitosan.

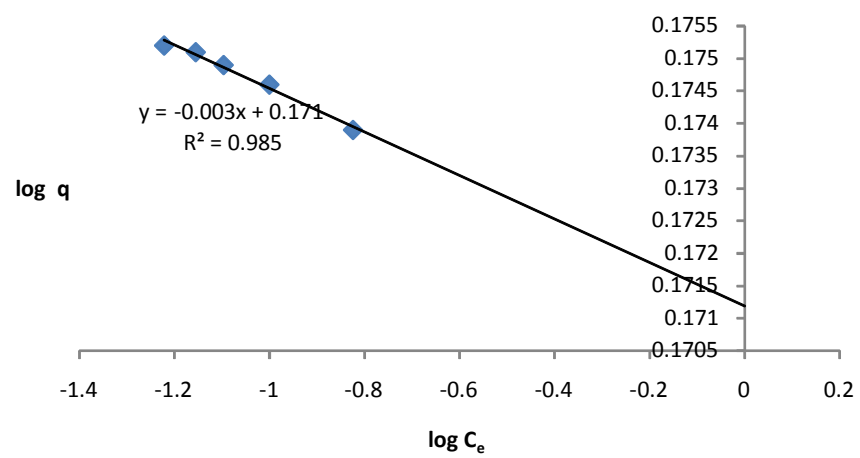

Figure 15. Freundlich isotherm of $\mathrm{Cu}(\mathrm{II})$ onto commercial chitosan. 


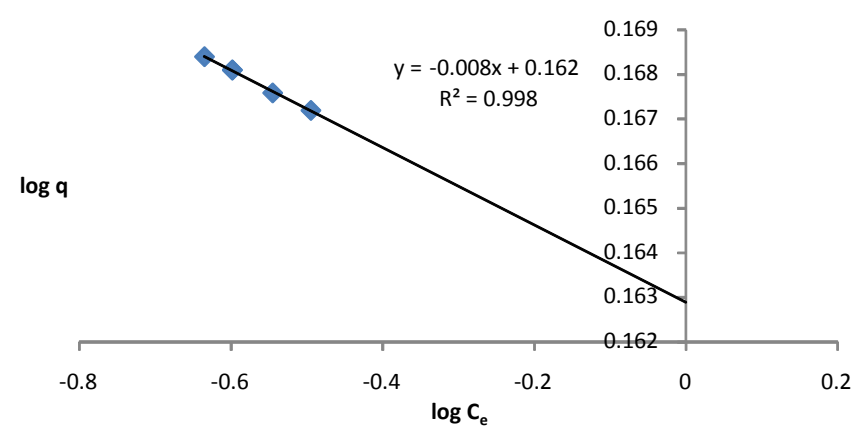

Figure 16. Freundlich isotherm of $\mathrm{Cu}(\mathrm{II})$ onto local chitosan.

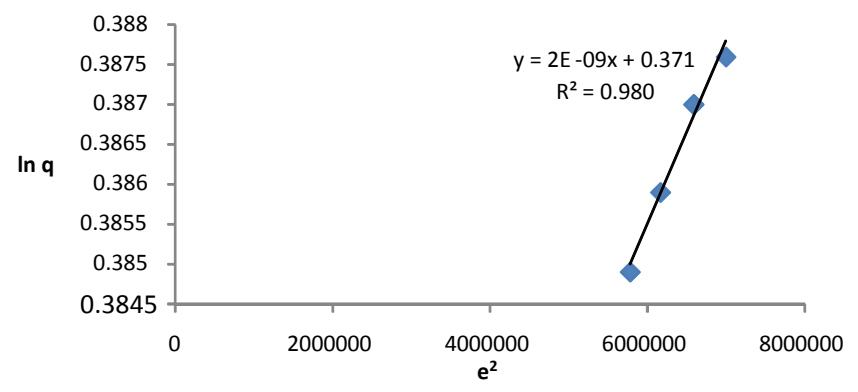

Figure 17. Dubinin-Raduskevich isotherm for $\mathrm{Cu}(\mathrm{II})$ onto local developed chitosan.

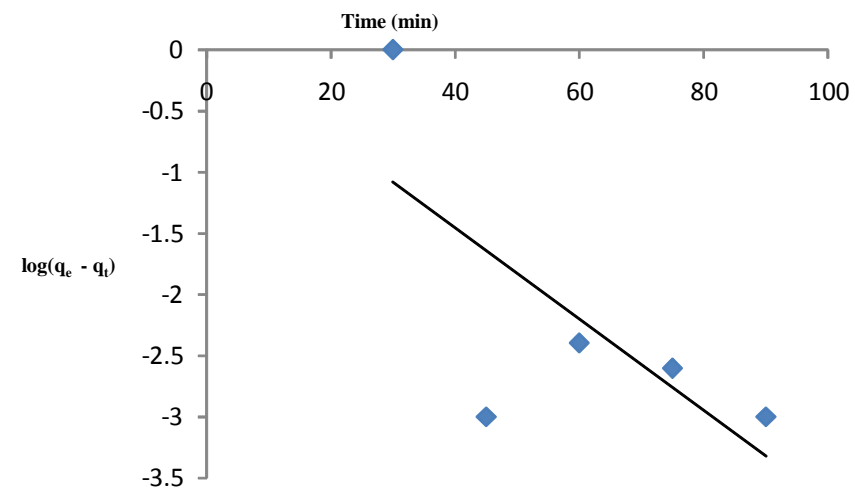

Figure 18. Pseudo-first-order model for adsorption of $\mathrm{Cu}(\mathrm{II})$ onto commercial chitosan.

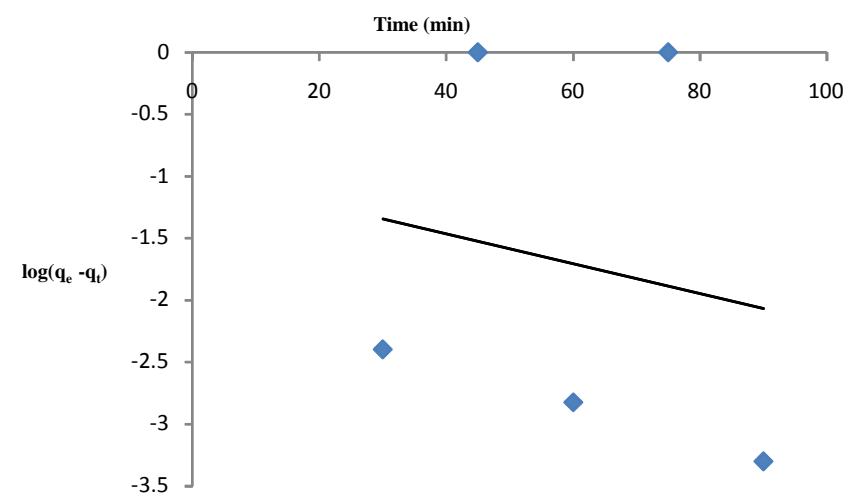

Figure 19. Pseudo-first-order model for adsorption of $\mathrm{Cu}^{2+}$ ion on local chitosan. 


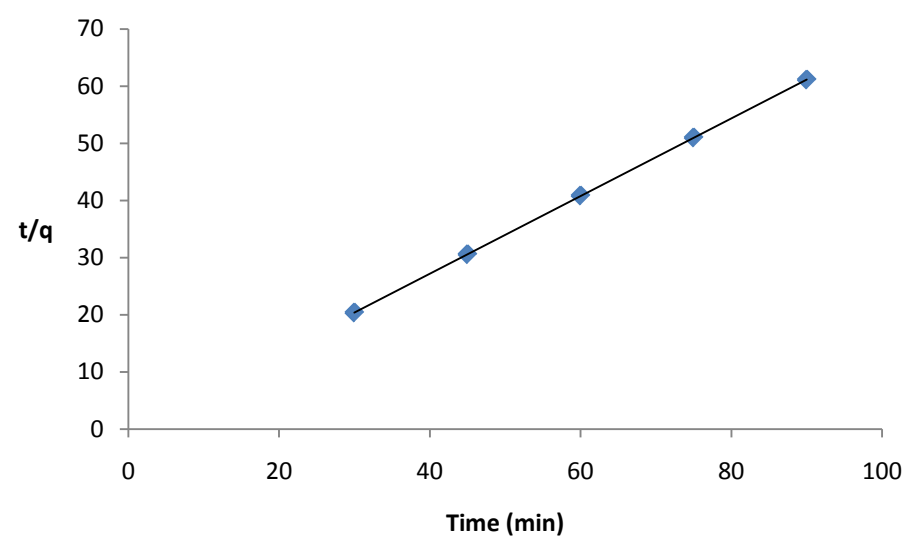

Figure 20. Pseudo-second-order reaction model for adsorption of $\mathrm{Cu}^{2+}$ ion onto local chitosan.

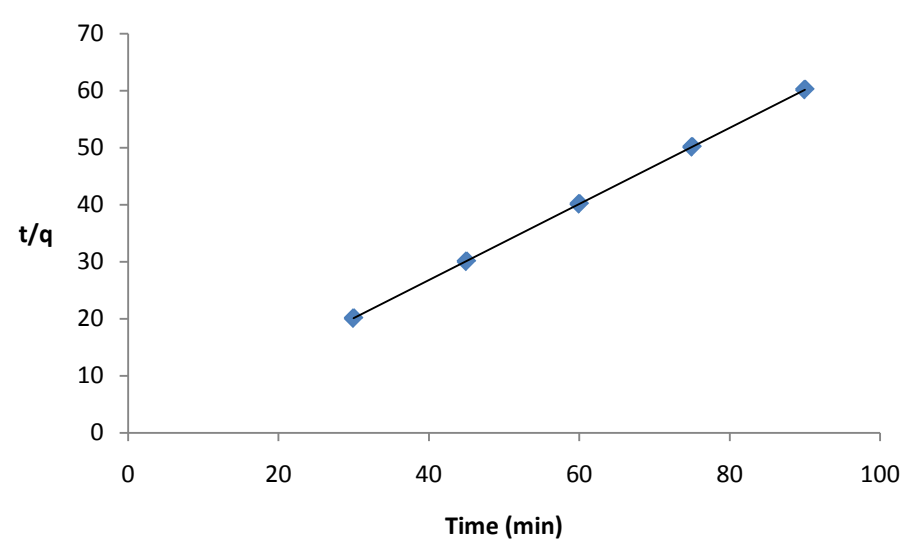

Figure 21. Pseudo-second-order reaction model for adsorption of $\mathrm{Cu}^{2+}$ ion on commercial chitosan.

Table 10. Coefficient of empirical kinetic models for locally developed and commercial chitosan.

\begin{tabular}{|c|c|c|c|c|c|c|c|c|}
\hline \multirow[b]{2}{*}{ Adsorbent } & \multirow[b]{2}{*}{ Metal } & \multicolumn{2}{|c|}{ Pseudo-first-order reaction model } & \multirow[b]{2}{*}{$\mathrm{k}_{1}$} & \multicolumn{2}{|c|}{ Pseudo-second-order reaction model } & \multirow[b]{2}{*}{$\mathrm{R}^{2}$} & \multirow[b]{2}{*}{$\mathrm{k}_{2}$} \\
\hline & & qecal. & $\mathrm{q}_{\mathrm{e}} \exp$ & & $\mathrm{q}_{\mathrm{e}} \mathrm{cal}$ & $\mathrm{q}_{\mathrm{e}} \exp$ & & \\
\hline $\mathrm{C}-\mathrm{C}$ & $\mathrm{Cu}^{2+}$ & 1.096 & 1.4965 & 0.104 & 1.4993 & 1.4965 & 0.999 & 10.35 \\
\hline L-C & $\mathrm{Cu}^{2+}$ & 0.1042 & 1.4735 & 0.085 & 1.4728 & 1.4735 & 0.999 & 66.02 \\
\hline
\end{tabular}

\section{Conclusion}

Chitosan was produced from crab shell to remove $\mathrm{Cu}(\mathrm{II})$ from aqueous solution. Pseudo-second-order kinetics model was the better model to describe the adsorption behavior of copper ion. The adsorption data for $\mathrm{Cu}(\mathrm{II})$ were well fitted to Langmuir, Freundlich and Elovich isotherm model.

\section{References}

[1] Crini, G. (2008) Application of Chitosan, a Natural Aminopolysaccharide, for Dye Removal from Aqueous Solutions by Adsorption Processes Using Batch Studies: A Review of Recent Literature. Progress in Polymer Science, 33, 399447. http://dx.doi.org/10.1016/j.progpolymsci.2007.11.001

[2] Krajewska, B. (2001) Diffusion of Metal Ions through Gel Chitosan Membranes. Reactive and Functional Polymers, 47, 37-47. http://dx.doi.org/10.1016/S1381-5148(00)00068-7

[3] Majeti, N.V. and Kumar, R. (2000) A Review of Chitin and Chitosan Applications. Reactive and Functional Polymers, 46, 1-27. http://dx.doi.org/10.1016/S1381-5148(00)00038-9 
[4] Guibal, E. (2004) Interactions of Metal Ions with Chitosan-Based Sorbents: A Review. Separation and Purification Technology, 38, 43-74. http://dx.doi.org/10.1016/j.seppur.2003.10.004

[5] Varma, J.A., Deshpande, S. and Kennedy, J. (2004) Metal Complexation by Chitosan and Its Derivatives: A Review. Carbohydrate Polymers, 55, 77-93. http://dx.doi.org/10.1016/j.carbpol.2003.08.005

[6] Wan, M.W., Kan, C.C., Rogel, B.D. and Dalida, M.L.P. (2010) Adsorption of Copper (II) and Lead (II) Ions from Aqueous Solution on Chitosan-Coated Sand. Carbohydrate Polymers, 80, 891-899. http://dx.doi.org/10.1016/j.carbpol.2009.12.048

[7] Vold, I.M.N., Varum, K.M., Guibal, E. and Smidsrod, O. (2003) Binding of Ions to Chitosans Electivity Studies. Carbohydrate Polymers, 54, 471-477. http://dx.doi.org/10.1016/j.carbpol.2003.07.001

[8] Igwe, J.C. and Abia, A.A. (2006) A Bioseparation Process for Removing Heavy Metals from Waste Water Using Biosorbents. African Journal of Biotechnology, 5, 167-1179.

[9] Beppu, M.M., Arruda, E.J., Vieira, R.S. and Santos, N.N. (2004) Adsorption of Cu(II) on Porous Chitosan Membranes Functionalized with Histidine. Journal of Membrane Science, 240, 227-235. http://dx.doi.org/10.1016/j.memsci.2004.04.025

[10] Zeng, X.F. and Ruckenstein, E. (1996) Supported Chitosan-Dye Affinity Membranes and Their Protein Adsorption. Journal of Membrane Science, 117, 271-278. http://dx.doi.org/10.1016/0376-7388(96)00079-8

[11] Dalida, M.L.P., Mariano, A.F.V., Futalan, C.M., Kan, C.C., Tsai, W.C. and Wan, M.W. (2011) Adsorptive Removal of $\mathrm{Cu}(\mathrm{II})$ from Aqueous Solutions Using Non-Crosslinked and Crosslinked Chitosan-Coated Bentonite Beads. Desalination, 275, 154-159. http://dx.doi.org/10.1016/j.desal.2011.02.051

[12] McKay, G., Blair, H.S. and Findon, A. (1989) Equilibrium Studies for the Sorption of Metal Ions onto Chitosan. Indian Journal of Chemistry, 28A, 356.

[13] Sağ, Y. and Aktay, Y. (2002) A Comparative Study for the Sorption of Cu(II) Ions by Chitin and Chitosan: Application of Equilibrium and Mass Transfer Models. Separation Science and Technology, 37, 2801-2822. http://dx.doi.org/10.1081/SS-120005467

[14] Malek, A. and Farooq, S. (1996) Comparison of Isotherm Models for Hydrocarbon Adsorption on Activated Carbon. AIChE Journal, 42, 3191-3201. http://dx.doi.org/10.1002/aic.690421120

[15] Langmuir, I. (1916) The Constitution and Fundamental Properties of Solids and Liquids: Part I. Solids. Journal of the American Chemical Society, 38, 2221-2295. http://dx.doi.org/10.1021/ja02268a002

[16] Ozmen, M., Can, K., Akin, I., Arslan, G., Tor, A., Cengeloglu, Y. and Ersoz, M. (2009) Surface Modification of Glass Beads with Glutaraldehyde: Characterization and Their Adsorption Property for Metal Ions. Journal of Hazardous Materials, 171, 594-600. http://dx.doi.org/10.1016/j.jhazmat.2009.06.045

[17] Elovich, S.Y. and Larinov, O.G. (1962) Theory of Adsorption from Solutions of Non Electrolytes on Solid (I) Equation Adsorption from Solutions and the Analysis of Its Simplest Form, (II) Verification of the Equation of Adsorption Isotherm from Solutions. Izvestiya Akademii Nauk SSSR, Otdelenie Khimicheskikh Nauk, 2, 209-216.

[18] Tempkin, M.I. and Pyzhev, V. (1940) Kinetics of Ammonia Synthesis on Promoted Iron Catalyst. The Journal of Physical Chemistry, 12, 327-356.

[19] Aharoni, C. and Ungarish, M. (1977) Kinetics of Activated Chemisorption. Part 2: Theoretical Models. Journal of the Chemical Society, Faraday Transactions, 73, 456-464. http://dx.doi.org/10.1039/f19777300456

[20] Ho, Y.S., Ng, J.C.Y. and McKay, G. (2000) Kinetics of Pollutant Sorption by Biosorbents: Review. Separation \& Purification Reviews, 29, 189-232. http://dx.doi.org/10.1081/SPM-100100009

[21] Liu, X.S., Cheng, Z.H. and Ma, W. (2009) Removal of Copper by a Modified Chitosan Adsorptive Membrane. Frontiers of Chemical Engineering in China, 3, 102-106. http://dx.doi.org/10.1007/s11705-009-0123-7

[22] Swapp, S. (2012) Scanning Electron Microscopy (SEM). http://serc.carleton.edu/research_education/geochemsheets/techniques/SEM.html

[23] Goldberg, S. (2005) Equations and Models Describing Adsorption Processes in Soils. Soil Science Society of America, Madison.

[24] Egerton, R.F. (2005) Physical Principles of Electron Microscopy: An Introduction to TEM, SEM, and AEM. Springer, Berlin. http://dx.doi.org/10.1007/b136495

[25] Ho, Y.S. (2006) Second-Order Kinetic Model for the Sorption of Cadmium onto Tree Fern: A Comparison of Linear and Non-Linear Methods. Water Research, 40, 119-125. http://dx.doi.org/10.1016/j.watres.2005.10.040

[26] Atkins, P.W. (1985) Physical Chemistry. 5th Edition, Oxford University Press, New York, 122-124. 


\section{Nomenclature}

$C_{0}$ initial concentration of metal ion in the liquid phase (mg/L)

$C_{e}$ equilibrium concentration of metal ion in the liquid phase (mg/L)

$k_{1}$ rate constant of pseudo-first order adsorption $\left(\mathrm{min}^{-1}\right)$

$k_{2}$ rate constant of pseudo-second order adsorption $\left(\mathrm{g} \cdot \mathrm{mg}^{-1} \cdot \mathrm{min}^{-1}\right)$

$K_{F}$ Freundlich isotherm constant is in (mg/g)

$b$ Langmuir isotherm constant $(\mathrm{L} / \mathrm{mg})$

$m$ amount of chitosan membrane (g)

$n$ number of experimental data

$q$ adsorption amount (mg/g)

$q_{e}$ adsorption amount at equilibrium (pseudo-second order equation constant) (mg/g)

$a$ maximum adsorption capacity (Langmuir isotherm constant) (mg/g)

$q_{t}$ adsorption amount at time $\mathrm{t}(\mathrm{mg} / \mathrm{g})$

$t$ time (min)

$V$ volume of the solution (L)

$K_{E}$ is the Elovich equilibrium constant $(\mathrm{L} / \mathrm{mg})$

$K$ is the Dubinin-Radushkevich constant $\left(\mathrm{kJ}^{2} / \mathrm{mol}\right)$ 